\title{
Characterization of the T-cell subpopulations in the granulation tissues of chronic suppurative otitis media
}

\author{
BING WANG, YING CHENG and MIN XU \\ Department of Otolaryngology, Head and Neck Surgery, The Second Affiliated Hospital, \\ Xi'an Jiaotong University, Xi'an, Shaanxi 710004, P.R. China \\ Received January 18, 2016; Accepted April 5, 2016
}

DOI: $10.3892 /$ br.2016.657

\begin{abstract}
The present study aimed to investigate the potential involvement of specific T-cell subpopulations in granulation tissue formation in chronic suppurative otitis media (CSOM). Fifteen patients with CSOM were enrolled in this study. Granulation tissues were obtained from the middle ear cavity. Hematoxylin and eosin staining was performed for histopathological observation, and different T-cell subpopulations were characterized by immunohistochemistry. No evident association was identified between granulation tissue formation and disease course. The number of cluster of differentiation $8^{+}$ $\left(\mathrm{CD}^{+}\right) \mathrm{T}$ cells, forkhead box $\left.\mathrm{P}^{+}{ }^{+} \mathrm{FOXP}^{+}\right)$regulatory $\mathrm{T}$ (Treg) cells and $\mathrm{OX} 40^{+} \mathrm{T}$ cells were significantly higher in granulation tissues from patients with ear discharge within the last 6 months compared to those without $(\mathrm{P}<0.05)$. Fresh granulation tissues had more $\mathrm{CD}^{+} \mathrm{T}$ cells and FOXP3 ${ }^{+}$Treg cells compared to the mature granulation tissues $(\mathrm{P}<0.05)$. There was a differential abundance of specific T-cell subpopulations in the granulation tissues in CSOM with different disease courses or with ear discharge, suggesting that $\mathrm{T}$ cell-mediated cellular immunity is involved in lesion formation of CSOM.
\end{abstract}

\section{Introduction}

Chronic suppurative otitis media (CSOM) is characterized by a perforated tympanic membrane with recurrent or persistent drainage from the middle ear for $\geq 8$ weeks (1). Suppurative inflammatory reaction of the mucous membrane, periosteum and bone of the middle ear mastoid cavity involves a variety of cells, including neutrophils, eosinophils, lymphocytes, mononuclear macrophages and plasma cells. Purulent

Correspondence to: Dr Min Xu, Department of Otolaryngology, Head and Neck Surgery, The Second Affiliated Hospital, Xi'an Jiaotong University, 157 Xi Wu Road, Xi'an, Shaanxi 710004, P.R. China

E-mail: ent551205@163.com

Key words: chronic suppurative otitis media, granulation tissue, T-cell subpopulations, ear discharge secretions consist mainly of white blood cells, macrophages and bacterium.

The most prominent pathological feature of CSOM is the presence of different degrees of granulation tissues $(2,3)$. A nodular inflammatory lesion arises from the attic region of the middle ear mastoid cavity with consistent stimulation of the mucous membrane. Immature connective tissues are enriched with capillaries, which are primarily composed of compact mononuclear phagocytes and fibroblasts. Granulation tissues began to appear after 2-3 days of tissue injury, filling wounds or organizing foreign bodies. In the early stages of granulation formation, macrophages infiltrate into tissues and release a variety of inflammatory mediators such as platelet-derived growth factor, fibroblast growth factor, transforming growth factor- $\beta$, tumor necrosis factor (TNF) and interleukin-1 (IL-1); and further recruit and stimulate hyperplasia of fibroblasts and capillaries. Gradually, granulation tissues become mature as indicated by the absorbed moisture, reduction and disappearance of inflammatory cells, and capillary occlusion or reduction; and eventually the maturity of connective tissues and scar tissues. The present study investigated the potential involvement of $\mathrm{T}$ cells, and the associated immune response with granulation tissue formation in CSOM.

\section{Materials and methods}

Patients. A total of 15 patients ( 8 males and 7 females, aged 17-77 years old) with CSOM were included in the study. The duration of CSOM ranged from 6 months to $>30$ years (Table I). Nine patients were self-reported and diagnosed with ear discharge within the last 6 months (active phase), while 6 cases had no ear discharge within the last 6 months (stationary phase) (4). All the patients underwent surgery in the Second Affiliated Hospital of Xi'an Jiaotong University (Xi'an, China). Bacterial culture was performed prior or during surgery. Informed consent was obtained from all the patients, and the study protocol was approved by the Ethics Committee of Xi'an Jiaotong University.

Granulation tissue sampling. Granulation tissue specimens were collected from the sinus, mastoid cavity or attic during surgery. Immediately following excision, granulation tissues were immersed in 4\% formalin; and subsequently washed with Tris-buffered saline with Tween-20 (TBST; pH 7.4), 
dehydrated, embedded in paraffin wax and cryostat sectioned into slices.

Hematoxylin and eosin $(H \& E)$ staining. Paraffin-embedded granulation tissue sections were stained with H\&E according to standard protocols. Histology was determined by two pathologists.

Immunohistochemistry and cell counting. Paraffin sections were placed in an oven at $60^{\circ} \mathrm{C}$ overnight and dewaxed in xylene three times; subsequently the sections were rehydrated through a graded alcohol series (100, 95, 90, 75 and 50\%), washed with distilled water, and finally, washed with TBST three times. These sections were treated with $3 \% \mathrm{H}_{2} \mathrm{O}_{2}$ for $10 \mathrm{~min}$ at room temperature to eliminate endogenous peroxidase. The sections were placed in a pressure kettle with $0.01 \mathrm{~mol} / 1$ citrate buffer for antigen retrieval. Subsequently, nonspecific protein was blocked with $5 \%$ goat serum for $30 \mathrm{~min}$, followed by reaction with cluster of differentiation 4 (CD4; cat. no. IS649; 1:180; monoclonal mouse anti-human), CD8 (cat. no. IS623; 1:40; monoclonal mouse anti-human) (both Dako, Glostrup, Denmark), forkhead box P3 (FOXP3; 1:20; monoclonal), OX40 (1:50; monoclonal) (both eBioscience, Inc., San Diego, CA, USA) and granzyme B (Novocastra, Newcastle upon Tyne, UK) antibodies at $4^{\circ} \mathrm{C}$ overnight. After washing three times with TBST for 5 min each time, sections were subsequently incubated with the appropriate secondary antibodies (Envision; Dako), stained with diaminobenzidine (DAB; alkaline phosphatase was used for FOXP3 staining), and counterstained with hematoxylin. Slides were observed under a microscope (CH20BIMF200; Olympus, Tokyo, Japan).

Five fields were randomly observed (magnification, x200) in each tissue section to count the positively stained cells, and the average was calculated. The cytomembrane of $\mathrm{CD}^{+}$ $\mathrm{T}$ cells and $\mathrm{CD} 4^{+} \mathrm{T}$ cells stained brown-yellow. Granyzme B-positive cells were brown-yellow granule stained in cytoplasma, while $\mathrm{OX} 40^{+} \mathrm{T}$ cells were brown-yellow granule stained in the cytomembrane and cytoplasma. The nucleus of $\mathrm{FOXP}^{+}$regulatory $\mathrm{T}$ (Treg) cells stained blue.

Statistical analysis. Data were analyzed using SPSS 18.0 software (SPSS, Inc., Chicago, IL, USA) and are expressed as mean \pm standard deviation. Two-sample t-test was used for statistical analysis. $\mathrm{P}<0.05$ was considered to indicate a statistically significant difference.

\section{Results}

Granulation tissue status has no correlation with CSOM disease course. Granulation tissue status was first identified by H\&E staining. As shown in Fig. 1A, a patient with 6 months of CSOM showed increased fibroblast growth, capillary blockage and inflammatory cell infiltration (mature granulation tissues). A large number of capillaries and inflammatory cell infiltration were also observed in 1 patient with 30 years of CSOM (mature granulation tissue; Fig. 1B). Two cases with 10-20 years of CSOM had experienced a recurrence within the past month. In 1 case, $\mathrm{H} \& \mathrm{E}$ staining revealed decreased capillaries and fibroblasts at the center surrounded by fresh granulation tissues (Fig. 1C). Notably, fresh granulation tissues,
Table I. Patient characteristics, disease course and status of granulation tissues.

\begin{tabular}{llcll}
\hline Patient no. & Gender & $\begin{array}{c}\text { Age, } \\
\text { years }\end{array}$ & \multicolumn{1}{c}{$\begin{array}{c}\text { Disease } \\
\text { course }\end{array}$} & $\begin{array}{c}\text { Status of } \\
\text { granulation } \\
\text { tissues }\end{array}$ \\
\hline 1 & F & 45 & 5 years & Mature \\
2 & F & 17 & 15 years & Mature \\
3 & M & 32 & 6 months & Mature \\
4 & F & 55 & 30 years & Fresh \\
5 & M & 60 & 30 years/17 years & Mature \\
6 & M & 77 & 13 years & Fresh \\
7 & M & 58 & 13 years & Mature \\
8 & F & 47 & 16 years & Fresh \\
9 & M & 36 & 28 years & Mature \\
10 & F & 70 & 30 years & Fresh \\
11 & F & 39 & 10 years/1 year & Mature \\
12 & M & 21 & 8 years & Fresh \\
13 & F & 55 & 14 years/1 month & Fresh \\
14 & M & 22 & 10 years/1 month & Mature \\
15 & M & 68 & 20 year & Mature \\
\hline
\end{tabular}

${ }^{\mathrm{a}}$ First instance/recurrence. F, female; M, male.

Table II. T-cell subtypes in granulation tissues of chronic suppurative otitis media.

T-cell subtypes Lymphocytes, no.

$\begin{array}{lc}\mathrm{CD}^{+} & 7.1 \pm 5.7 \\ \mathrm{CD}^{+} & 27.0 \pm 30.0 \\ \text { Granzyme B positive } & 3.1 \pm 6.7 \\ \text { Forkhead box P3 } & \\ \mathrm{OX}^{+} & 22.6 \pm 22.5 \\ & 2.1 \pm 2.0\end{array}$

$\mathrm{CD}$, cluster of differentiation.

mature granulation tissues and even necrotic tissues could be simultaneously observed in a specimen. Characterization of granulation tissues in H\&E-stained specimens from other patients revealed that there was no correlation between the deteriorative status of granulation tissues with the duration of the disease (disease course) (Fig. 1D). Patients with a longer history of CSOM may not have mature granulation tissues, while patients with a shorter history of CSOM may have mature granulation tissues. The status of granulation tissues in each patient is shown in Table I.

Immunohistochemistry and T-cell subtypes in granulation tissues. Five fields in each specimen were randomly selected at high magnification. The mean positive cell count of these five fields was considered as the mean number of positive cells of the specimen. In all 15 specimens, the mean number of $\mathrm{CD}^{+}$ T cells was $27.0 \pm 30.0$, while the mean number of FOXP3 ${ }^{+}$Treg cells was $22.6 \pm 22.5$; and these results were significantly higher 

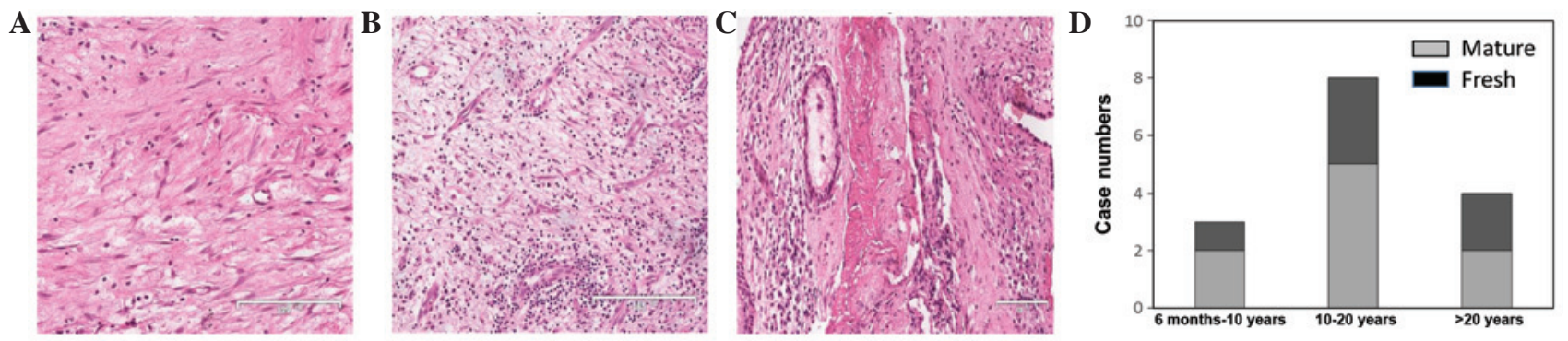

Figure 1. Hematoxylin and eosin staining of granulation tissues from 3 CSOM patients with different lengths of disease course. Patients with CSOM for (A) 6 months, (B) 30 years and (C) 10 years. (D) The number of fresh and mature granulation tissues in CSOM with different lengths of disease course. CSOM, chronic suppurative otitis media.

A

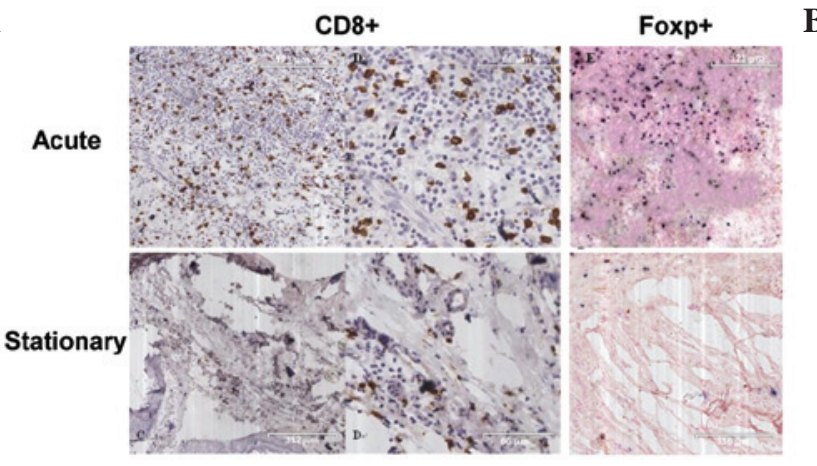

B

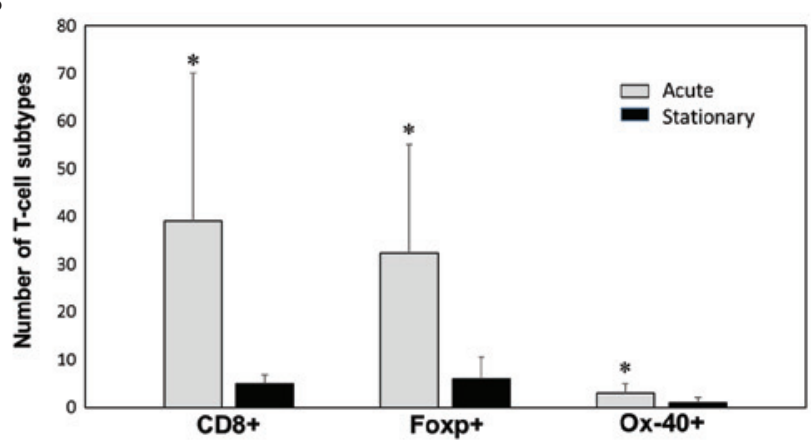

Figure 2. Immunohistochemistry staining of granulation tissues in chronic suppurative otitis media in acute and stationary phases. (A) CD8 ${ }^{+} \mathrm{T}$ cell and FOXP T-cell staining; (B) the number of different T-cell subtypes in granulation tissues in CSOM in acute $(\mathrm{n}=9)$ and stationary $(\mathrm{n}=6)$ phases. ${ }^{*} \mathrm{P}<0.05$. CD8, cluster of differentiation 8; FOXP, forkhead box P.

A

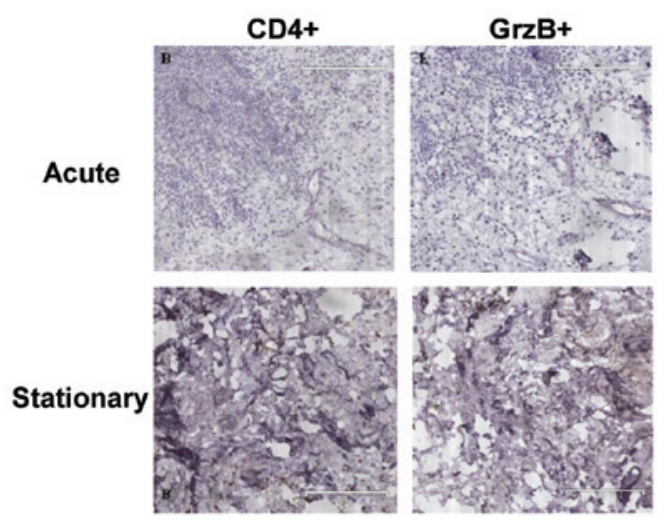

B

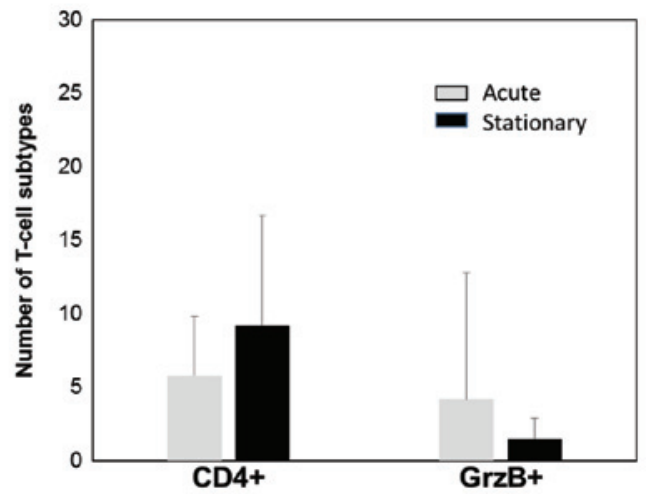

Figure 3. Immunohistochemistry staining of granulation tissues in CSOM in acute and stationary phases. (A) $\mathrm{CD}^{+} \mathrm{T}$ cell and GraZB ${ }^{+} \mathrm{T}-\mathrm{cell}$ staining; (B) the number of different T-cell subtypes in granulation tissues in CSOM in acute $(n=9)$ and stationary ( $=6)$ phases. CSOM, chronic suppurative otitis media; CD4, cluster of differentiation 4; GraZB, granzyme B.

compared to $\mathrm{CD}^{+} \mathrm{T}$ cells $(7.1 \pm 5.7)$, granzyme B-positive

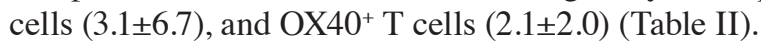

T-cell subtypes in granulation tissues of CSOM patients in stationary or active phases. Patients were grouped into stationary (without ear discharge within the last 6 months, $\mathrm{n}=6$ ) and active (with ear discharge within the last 6 months, $\mathrm{n}=9$ ) phases, according to the guidelines for diagnosis and treatment of CSOM in China (2012) and electron microscopy identification of CSOM (4). Fig. 2A shows the CD8 and FOXP immunohistochemistry staining of granulation tissues from a patient with 30 years of CSOM and recent ear discharge (acute phase), and another patient with a 10-year history of CSOM and without ear discharge in the last 6 months.

There were significantly more $\mathrm{CD}^{+} \mathrm{T}$ cells $(39 \pm 31)$, $\mathrm{FOXP}^{+}$Treg cells $(32.3 \pm 22.8)$, and $\mathrm{OX} 40^{+}$cells $(2.9 \pm 2.1)$ in the granulation tissues from the CSOM patients in the acute phase compared to the stationary phase (all $\mathrm{P}<0.05$, Fig. $2 \mathrm{~B}$ ). There were few $\mathrm{CD}^{+} \mathrm{T}$ cells and granzyme B-positive cells in the granulation tissues in the acute phase compared to $\mathrm{CD}^{+}$and $\mathrm{FOXP}^{+}$cells (Fig. 3A). No significant difference was identified in the number of $\mathrm{CD} 4^{+} \mathrm{T}$ cells and granzyme B-positive cells between the granulation tissues in the acute and stationary phases ( $\mathrm{P}>0.05)$ (Fig. 3B). 
T-cell subtypes in fresh and mature granulation tissues. As characterized by H\&E staining, granulation tissues were classified into two types. Specimens that exhibited a large number of capillaries and inflammatory cell infiltration were classified as fresh granulation tissues (6 cases), while the remaining specimens were classified as mature granulation tissues (9 cases). The number of different T-cell subtypes in fresh and mature granulation tissues was counted. As shown in Table III, there were significantly more $\mathrm{CD}^{+} \mathrm{T}$ cells $(48 \pm 30)$ and FOXP ${ }^{+}$Treg cells $(41.3 \pm 22.8)$ in fresh granulation tissues compared to mature granulation tissues $(\mathrm{P}<0.05)$. By contrast, no significant differences were identified in the number of $\mathrm{CD} 4^{+} \mathrm{T}$ cells, granzyme B-positive cells and $\mathrm{OX} 40^{+} \mathrm{T}$ cells between the two groups $(\mathrm{P}>0.05)$.

\section{Discussion}

CSOM is an inflammatory-related chronic disease in the middle ear mastoid cavity with different granulation tissue phases. The present study revealed that the maturity of granulation tissues had no correlation with the disease course of CSOM. There was no evidence showing that the longer the duration is, the more mature the granulation tissues are. In a previous histopathological study of the temporal bone slice, granulation tissues formed in the inflammatory drainage in two different ways; and subsequently, effusion was gradually covered (2). The purpose of granulation tissue formation is to cover and organize effusion that could not be completely absorbed. In the local inflammatory response of CSOM, it is a persistent pathological course and acts as an important pathological sign. Scar tissues contain a small amount of fibroblasts and an abundant amount of collagen, which forms following apoptosis and absorption of granulation tissues. In this way, each CSOM occurrence leaves a mark in the middle ear cavity. A mixture of granulation tissues and scars in the middle ear cavity would form following several acute attacks of the disease.

Macrophages, $\mathrm{T}$ cells and $\mathrm{B}$ cells were presented time-dependently in the acute inflammatory response in acute otitis media (AOM) (5). Different subtypes of T lymphocyte were identified in various lesions in patients with CSOM and cholesteatoma (6). Macrophages were considered to be the firsT cells to invade the tissue following AOM induction (5), and these macrophages in the middle ear may have a profound influence in regulating immune response in the middle ear in patients who have otitis media with effusion (7). $\mathrm{CD}^{+} \mathrm{T}$ cells are known as mature T-helper cells that help regulate immune response and activate other immune cells by releasing T-cell cytokines. These cells are essential in B-cell antibody class switching, activation and growth of cytotoxic T cells, and enhancement of the bactericidal activity of phagocytes such as macrophages. $\mathrm{CD}^{+} \mathrm{T}$ cells could be observed in granulation tissues in all 15 cases in the present study. No significant difference was observed in the number of $\mathrm{CD}^{+} \mathrm{T}$ cells in different granulation tissue phases (fresh or mature), or in lesions of CSOM patients with or without recent ear discharge (acute or stationary phase).

However, the population of $\mathrm{CD}^{+}{ }^{+} \mathrm{T}$ cells expressing OX40 increased in granulation tissues in the acute phase of CSOM. OX40, also known as CD134, is a member of the superfamily
Table III. T-cell subtypes in fresh and mature granulation tissues of chronic suppurative otitis media.

\begin{tabular}{lcc}
\hline $\begin{array}{l}\text { T-cell } \\
\text { subtypes }\end{array}$ & $\begin{array}{c}\text { Fresh granulation } \\
\text { tissues, no. }(\mathrm{n}=6)\end{array}$ & $\begin{array}{c}\text { Mature granulation } \\
\text { tissues, no. }(\mathrm{n}=9)\end{array}$ \\
\hline $\mathrm{CD}^{+}$ & $6.3 \pm 4.5$ & $7.7 \pm 6.6$ \\
$\mathrm{CD}^{+}$ & $48 \pm 30^{\mathrm{a}}$ & $10.3 \pm 16.8$ \\
Granzyme B positive $^{+}$ & $1.5 \pm 0.8$ & $4.2 \pm 8.6$ \\
Forkhead box P3 $^{+}$ & $41.3 \pm 22.8^{\mathrm{a}}$ & $8.8 \pm 6.4$ \\
$\mathrm{OX}^{+}$ & $2.5 \pm 2.0$ & $1.9 \pm 2.0$ \\
\hline
\end{tabular}

${ }^{\mathrm{a}} \mathrm{P}<0.05$ vs. mature granulation tissues. $\mathrm{CD}$, cluster of differentiation.

of TNF receptors; which belongs to the type I transmembrane protein. OX40 was initially found on activated CD4 ${ }^{+}$ $\mathrm{T}$ cells $(8,9)$, but subsequent studies reported that $\mathrm{OX} 40$ is also expressed on activated $\mathrm{CD}^{+} \mathrm{T}$ cells and neutrophils $(8,10)$. OX40 expression levels on naive CD4 cells peaked 2-3 days after T-cell receptor (TCR) stimulation, and were downregulated 4-5 days after the initial TCR stimulation (11). OX40 expression on activated $\mathrm{CD}^{+}{ }^{+} \mathrm{T}$ cells was known to enable proliferating $\mathrm{T}$ cells to accumulate as differentiated effector cells. However, no significant difference was identified in the number of OX40-positive cells in fresh and mature granulation tissues.

FOXP3, also known as scurfin, is a protein involved in the immune system responses (12). This protein appears to function as a master regulator in the development and function of Treg cells, which generally turn down immune responses $(9,13,14)$. FOXP3 ${ }^{+}$is an important surface marker of activated $\mathrm{CD}^{+}{ }^{+} \mathrm{CD} 25^{+}$Treg. Activated FOXP3 ${ }^{+}$Treg may inhibit $\mathrm{T}$-cell activation and proliferation in immune responses (12). In the present study, FOXP3 ${ }^{+}$Treg expression levels were relatively higher in granulation tissues, particularly in specimens from patients with ear discharge within the last 6 months and patients with fresh granulation tissues. Similar results were reported by Germanidis et al (15) wherein $\mathrm{FOXP}^{+}$Treg was significantly downregulated in the remission of chronic hepatitis B virus and FOXP3 transcripts were positively correlated to the intensity of inflammation. Thus, higher expression levels of FOXP3 ${ }^{+}$Treg in acute inflammation and fresh granulation tissues could avoid excessive damage during an immune response. It has previously been reported that although there were no significant differences in immunoglobulin levels, patients treated with allergen immunotherapy had lower numbers of FOXP3 ${ }^{+}$ lymphocytes than patients that were not treated (16). The percentage of T lymphocyte with IL-7R (CD127 and CD132) increased in hypertrophic adenoid, which appeared to influence the number and function of lymphocytes in tonsils; and further influenced the course of chronic otitis media with effusion (10). The decline of memory $\mathrm{T}$ cells was considered a risk factor of chronic otitis media with effusion in adolescents (11). A previous study by Wang et al (17) revealed that $\mathrm{CD} 4^{+} \mathrm{CD} 25^{+} \mathrm{FOXP} 3^{+}$Treg cells were involved in chronic otitis media with effusion as immune cells for regulation. 
Another critical component of cellular immune response is $\mathrm{CD}^{+} \mathrm{T}$ lymphocytes, which are effector cells that could kill infected and cancer cells. In the present study, $\mathrm{CD}^{+} \mathrm{T}$ cells could be observed in granulation tissues from all 15 cases, suggesting that $\mathrm{T}$ cell-mediated cellular immune response is involved in the inflammatory immune process of the disease. Known as cytotoxic $\mathrm{T}$ cells, $\mathrm{CD}^{+} \mathrm{T}$ cells could recognize targeT cells with surface antigen of major histocompatibility complex class I molecules; and subsequently, destroy these cells. Once activated, $\mathrm{CD}^{+} \mathrm{T}$ cells would release perforin and granzymes, which could trigger the caspase cascade and eventually lead to apoptosis. Granzymes are serine proteases released by cytoplasmic granules within cytotoxic $\mathrm{T}$ cells, and are natural killer cells. They can induce apoptosis of virus-infected cells (18). Granzyme B is one of the most important types of granzyme (19), which is secreted along with the pore-forming protein, perforin, to mediate apoptosis in targeT cells (20). A second way to induce apoptosis is via the binding of the Fas ligand (FasL) expressed on the surface of activated T cells and Fas molecules expressed on the surface of targeT cells. The present experimental results revealed that $\mathrm{CD}^{+} \mathrm{T}$-cell expression levels were significantly high, while granzyme B-positive cell expression levels were relatively low. Therefore, $\mathrm{CD}^{+} \mathrm{T}$-cell accumulation in lesions of CSOM may induce apoptosis mainly via the Fas/FasL pathway.

In conclusion, there was no evident association between the course of the disease and granulation tissue formation. $\mathrm{T}$ cell-mediated cellular immunity was involved in granulation tissue formation in CSOM.

\section{Acknowledgements}

The present study was financially supported by the Cancer Research Institute of the Medical School of Xi'an Jiaotong University.

\section{References}

1. Afolabi OA, Salaudeen AG, Ologe FE, Nwabuisi C and Nwawolo CC: Pattern of bacterial isolates in the middle ear discharge of patients with chronic suppurative otitis media in a tertiary hospital in North central Nigeria. Afr Health Sci 12: 362-367, 2012.

2. Paparella MM, Schachern PA, Yoon TH, Abdelhammid MM, Sahni R and da Costa SS: Otopathologic correlates of the continuum of otitis media. Ann Otol Rhinol Laryngol Suppl 148: 17-22, 1990.

3. da Costa SS, Paparella MM, Schachern PA, Yoon TH and Kimberley BP: Temporal bone histopathology in chronically infected ears with intact and perforated tympanic membranes. Laryngoscope 102: 1229-1236, 1992.
4. Kaya E, Dag I, Incesulu A, Gurbuz MK, Acar M and Birdane L: Investigation of the presence of biofilms in chronic suppurative otitis media, nonsuppurative otitis media, and chronic otitis media with cholesteatoma by scanning electron microscopy. ScientificWorldJournal 2013: 638715, 2013.

5. Forséni M, Hansson GK, Bagger-Sjöbäck D and Hultcrantz M Infiltration of immunocompetent cells in the middle ear during acute otitis media: A temporal study. Am J Otol 20: 152-157, 1999.

6. Kähönen K, Palva T, Bergroth V, Konttinen YT and Reitamo S: Immunohistochemical identification of inflammatory cells in secretory and chronic otitis media and cholesteatoma using monoclonal antibodies. Acta Otolaryngol 97: 431-436, 1984.

7. Yamanaka T, Bernstein JB, Cumella J, Parker C and Ogra PL: Immunologic aspects of otitis media with effusion: Characteristics of lymphocyte and macrophage reactivity. J Infect Dis 145: 804-810, 1982.

8. Baumann R, Yousefi S, Simon D, Russmann S, Mueller C and Simon HU: Functional expression of CD134 by neutrophils. Eur J Immunol 34: 2268-2275, 2004.

9. Gramaglia I, Weinberg AD, Lemon M and Croft M: Ox-40 ligand: A potent costimulatory molecule for sustaining primary CD4 T cell responses. J Immunol 161: 6510-6517, 1998.

10. Żelazowska-Rutkowska B, Wysocka J, Ratomski K, Kasprzycka E and Skotnicka B: Increased percentage of T cells with the expression of CD127 and CD132 in hypertrophic adenoid in children with otitis media with effusion. Eur Arch Otorhinolaryngol 269: 1821-1825, 2012.

11. Sharma SK, Casey JR and Pichichero ME: Reduced memory $\mathrm{CD} 4^{+} \mathrm{T}$-cell generation in the circulation of young children may contribute to the otitis-prone condition. J Infect Dis 204: 645-653, 2011.

12. Sakaguchi S, Miyara M, Costantino CM and Hafler DA: FOXP3 ${ }^{+}$ regulatory $\mathrm{T}$ cells in the human immune system. Nat Rev Immunol 10: 490-500, 2010.

13. Redmond WL, Ruby CE and Weinberg AD: The role of OX40-mediated co-stimulation in T-cell activation and survival. Crit Rev Immunol 29: 187-201, 2009.

14. Devaud C, Darcy PK and Kershaw MH: Foxp3 expression in $\mathrm{T}$ regulatory cells and other cell lineages. Cancer Immunol Immunother 63: 869-876, 2014.

15. Germanidis G, Argentou N, Hytiroglou P, Vassiliadis T, Patsiaoura K, Germenis AE and Speletas M: Liver FOXP3 and PD1/PDL1 expression is down-regulated in chronic HBV hepatitis on maintained remission related to the degree of inflammation. Front Immunol 4: 207, 2013.

16. Coria-Ramírez É, Vargas-Camaño ME, Guido-Bayardo RL, García-Castillo G, Zepeda-García C, Mèndez-Medina J and Castrejón-Vázquez MI: Levels of $\mathrm{CD}^{+}$and FOXP $3^{+}$lymphocytes in patients with allergic rhinitis. Rev Alerg Mex 60: 5-10, 2013 (In Spanish).

17. Wang DN, Li J, ZhaoSQ, Wang Y and Yang L: Role of FOXP3 CD4 CD25 T cells in otitis media with effusion. Chinese Archives of Otolaryngology-Head and Neck Surgery 20: 126-128, 2013.

18. Mallett S, Fossum S and Barclay AN: Characterization of the MRC OX40 antigen of activated CD4 positive T lymphocytes -a molecule related to nerve growth factor receptor. EMBO J 9: 1063-1068, 1990.

19. Ewen CL, Kane KP and Bleackley RC: A quarter century of granzymes. Cell Death Differ 19: 28-35, 2012.

20. Chowdhury D and Lieberman J: Death by a thousand cuts: Granzyme pathways of programmed cell death. Annu Rev Immunol 26: 389-420, 2008. 